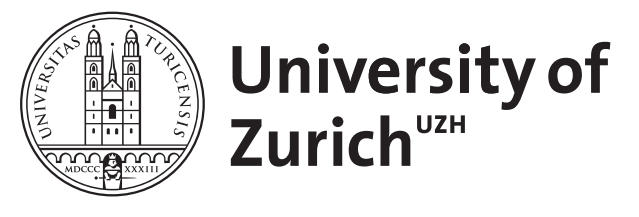

\title{
The pragmatics of word learning
}

Grassmann, Susanne

\begin{abstract}
Children use and integrate a variety of information when learning novel words. Most strikingly, children are skillful in drawing inferences about speakers' intentions. This chapter reviews the current state of affairs regarding the wide variety of pragmatic information that children employ in word learning. Current debates on whether seemingly pragmatic phenomena in word learning should be explained by simpler processes are addressed throughout the chapter. Suggestions for future research directions are made. Finally, I suggest that in order to acknowledge the role that pragmatic information plays in word learning, the field needs to come to an agreement on what it is that children acquire in word learning: word-object/concept-associations or means to communicate and direct other's attention to certain objects?
\end{abstract}

DOI: https://doi.org/10.1075/tilar.10.09gra

Posted at the Zurich Open Repository and Archive, University of Zurich

ZORA URL: https://doi.org/10.5167/uzh-105106

Book Section

Published Version

Originally published at:

Grassmann, Susanne (2014). The pragmatics of word learning. In: Matthews, Danielle. Pragmatic development in first language acquisition. Amsterdam: John Benjamins, 139-160.

DOI: https://doi.org/10.1075/tilar.10.09gra 


\section{John Benjamins Publishing Company}

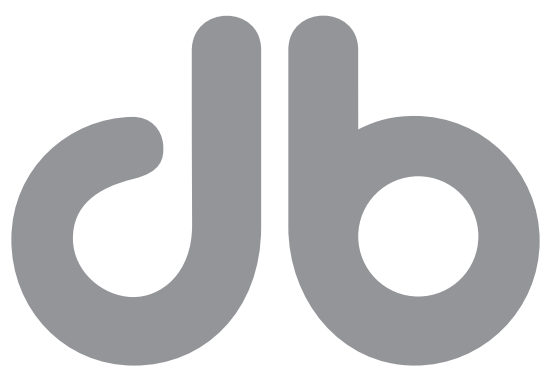

This is a contribution from Pragmatic Development in First Language Acquisition. Edited by Danielle Matthews.

(C) 2014. John Benjamins Publishing Company

This electronic file may not be altered in any way.

The author(s) of this article is/are permitted to use this PDF file to generate printed copies to be used by way of offprints, for their personal use only.

Permission is granted by the publishers to post this file on a closed server which is accessible to members (students and staff) only of the author's/s' institute, it is not permitted to post this PDF on the open internet.

For any other use of this material prior written permission should be obtained from the publishers or through the Copyright Clearance Center (for USA: www.copyright.com). Please contact rights@benjamins.nl or consult our website: www.benjamins.com Tables of Contents, abstracts and guidelines are available at www.benjamins.com 
CHAPTER 9

\title{
The pragmatics of word learning
}

\author{
Susanne Grassmann \\ University of Zurich
}

The reason for the basic role of observations [...] in the learning of language is their inter-subjective immediacy. [...] We learn the language from other people in shared circumstances. Somewhere [in the language learning process] there have to be non-verbal reference points, nonverbal circumstances that can be intersubjectively appreciated and associated with the appropriate utterance on the spot. [...] The child and the parent must both see red when the child learns 'red' and one of them must also see that the other sees red at the time.

(Quine, 1974:37)

Children use and integrate a variety of information when learning novel words. Most strikingly, children are skillful in drawing inferences about speakers' intentions. This chapter reviews the current state of affairs regarding the wide variety of pragmatic information that children employ in word learning. Current debates on whether seemingly pragmatic phenomena in word learning should be explained by simpler processes are addressed throughout the chapter. Suggestions for future research directions are made. Finally, I suggest that in order to acknowledge the role that pragmatic information plays in word learning, the field needs to come to an agreement on what it is that children acquire in word learning: word-object/concept-associations or means to communicate and direct other's attention to certain objects?

\section{Introduction}

Parents eagerly anticipate their child's first word. After becoming sophisticated non-verbal communicators (cf., Stephens \& Matthews, this volume), the big event typically comes about around the child's first birthday. Parents are amazed by their children's seemingly effortless language learning and philosophers and researchers from Augustine to Locke to Piaget, and to today's scholars have built theories and run experiments that aim to explain the phenomenon of lexical development. Researchers agree that children use a variety of information sources when 
identifying novel words' referents but, in line with the quote from Quine above, they give particular weight to the social-pragmatic information (cf., Diesendruck \& Patael, in press; Hall \& Waxman, 2004; Golinkoff et al., 2000; Golinkoff \& Hirsh-Paesk, 2006; Woodward \& Markman, 1998).

The core of this chapter catalogues the various kinds of pragmatic information that children are sensitive to and rely on when learning words. Besides reviewing studies that investigate children's sensitivity to one or another source of information that can be used to infer speakers' intentions, I will discuss why using this particular kind of information is indeed a pragmatic skill. At times I will present alternative non-pragmatic accounts, briefly outline theoretical debates, and point to open questions and potential ways to address them. Before turning to the empirical findings, the next section shall briefly introduce the main four theoretical perspectives on word learning.

\section{Theories of word learning}

One can broadly distinguish four theoretical accounts to children's word learning. Each of these accounts focuses on different processes in order to explain children's word learning.

First, constraints accounts suggest that word learning fundamentally rests on certain biases specifically destined for easing children's interpretation of novel words. For example, the whole object bias leads children to assume that novel words refer to whole objects rather than to parts or properties (cf., Markman, 1989; Golinkoff, Mervis, \& Hirsh-Pasek, 1994), and the mutual exclusivity bias leads them to assume that different words name different categories of objects (Markman \& Wachtel, 1988; Merriman \& Bowman, 1989). Second, basic associative learning mechanisms might be the driving force behind word learning (Smith, 2000). According to such an account, children simply associate salient sounds (words) with salient entities and events around them. Third, social-pragmatic accounts hold that children privilege information about speakers' intentions when inferring what a novel word means (Akthar \& Tomasello, 2000; Diesendruck \& Patael, in press; Tomasello, 2003). Fourth, in an attempt to unify theories of word learning, the Emergentist Coalition Model acknowledges the relevance and use of various kinds of information in children's word learning (Hollich et al., 2000). The general idea of this account is that relevance and weighting of information shifts over time during the first years of children's word learning. In particular, this account holds that children start out with associative word learning mechanisms but become proficient users of social-pragmatic information during their second year of life. 


\section{Pragmatic information children use in word learning}

In this section, I will catalogue the various kinds of pragmatic information that have been demonstrated over the past 20 years to be used by children when interpreting novel words.

Pragmatic information comprises everything in a word usage event that is explicitly or implicitly provided by the speaker (through language, intonation, gesture, and behavior) as well as in the context of the speaker's word use (in the physical context as well as in the prior discourse). Why are these kinds of information considered pragmatic? First, in order to use any of this information in word learning, children must draw an inference that a particular aspect of the word-usage event is relevant to the interpretation of a speaker's utterance. Second, beyond such a relevance inference, children must integrate the various aspects of the word usage event into one coherent interpretation of the speaker's intentions. Both processes are arguably pragmatic: they rely on the assumption that the speaker engages in an intentional action and that a coherent intention underlies his (multimodal) behavior.

\section{The speaker's gaze and joint attention}

A speaker's gaze reveals information about her attention and thereby is indicative of her communicative and non-communicative intentions, goals, and desires. Joint attention is the sophisticated coordination and mutual awareness of gaze and attention between child and speaker (Bakeman \& Adamson, 1984). The importance of understanding gaze and joint attention in word learning is apparent in the fact that infants' gaze following skills and the amount of time they spend in joint attention with caregivers are correlated with subsequent vocabulary size and language development (e.g., Brooks \& Meltzoff, 2008; Tomasello \& Farrar, 1986).

Using gaze in word learning is anything but trivial: the word learner has to (1) acknowledge the relevance of gaze information and (2) integrate the speaker's gaze and word-use into one coherent interpretation, namely that she is naming the gazed at or jointly focused on object. Given this complexity, it is not surprising that it takes children some months after they are able to follow gaze and engage in joint attention before they master using these skills in word learning.

At 10 months of age, infants ignore speaker's gaze but instead assign words to whatever object they themselves are looking at (Pruden, Hirsh-Pasek, Golinkoff, \& Hennon, 2006). By 12 months, infants begin attending to speakers' line of regard in word learning situations (Brand, 2000) but they do not yet use it in their interpretation of novel words (Hennon, Chung, \& Brown, 2000). However, 
13-month-olds do seek referential information in ambiguous situations (i.e., with more than one potential referent) by looking to the speaker in order to gain information as to which object she is referring to with a novel word (Vaish, Demir, \& Baldwin, 2011). Fourteen-month-olds orient towards gazed-at objects upon hearing a novel word (Houston-Price, Plunkett, \& Duffy, 2006) but only from about 18 to 24 months do infants reliably use gaze in order to identify the object that a speaker is naming (Baldwin, 1991, 1993; Baldwin et al., 1996; Brand, 2000; Moore, Angelopoulos, \& Bennett, 1999). Thus, during the second year of life, typically developing children develop an understanding that people look at the objects they are naming. Children with Autism Spectrum Disorder (ASD), however, tend to fail to employ the speaker's gaze when matching words and objects even at an older age (Baron-Cohen, Baldwin, \& Crowson, 1997, cf., Norbury, this volume).

But children do not blindly assign novel names to the object a speaker is gazing at. Rather they truly integrate gaze, utterance and other aspects of the naming event into a coherent interpretation of the speaker's referential intentions. For example, Nurmsoo and Bloom (2008) demonstrated that 2- and 4-year-olds identified or excluded the gazed-at object as the referent of a novel word based on the sentential frame in which a speaker used it: when the speaker said, There is the nurmy. children identified the object in the speaker's line of regard as the referent. But when she said, Where is the nurmy? then they excluded this very object. In a study by Grassmann, Stracke, \& Tomasello (2009) children also excluded the object a speaker looked at as the referent of a novel word when the pragmatics of the situation suggested such exclusion: when the speaker expressed excitement while looking at an object that was old news and thus unlikely to elicit such excitement.

Interestingly, children explicitly do not use speakers' gaze for interpreting novel words when other, presumably more reliable, information is available. For example, toddlers tend to ignore gaze when it is in conflict with the child's knowledge of lexical conventions or when a speaker looks at a familiar object and uses a novel word (Graham, Nilsen, Collins, \& Olineck, 2010; Jaswal, 2010; Jaswal \& Hansen, 2006).

\section{Pointing gestures}

In order to learn a word by identifying its referent as what a speaker is pointing at, the word learner must (1) attend to both the gesture and the word and (2) integrate them into one coherent interpretation. Already infants as young as 13-months assume that pointing and naming co-refer - as indicated by the 
fact that they extensively scan the objects presented to them when pointing and naming are mismatched (Gliga \& Csibra, 2009). Such enhanced attention to the scene might simply signal surprise, but it might also be a sign of the infants' attempt to integrate the current information. The latter would be a prerequisite for word learning. Infants seem to start using pointing in word learning at about the same age they begin relying on gaze, around 18 months of age (Briganti \& Cohen, 2011). But, when a speaker points at a novel object while naming it, this enhances children's word learning as compared to when she only gazes at it (Booth, McGregor, \& Rohlfing, 2008).

Clear evidence for children's integration of pointing and naming comes from studies that investigate children's reference resolution in situations of contradictory pointing and naming (Grassmann \& Tomasello, 2010; Grassmann, Magister, \& Tomasello, 2011; Thompson \& Masaro, 1986, 1994; but see Jaswal \& Hansen, 2006). These studies varied the ambiguity/ referential strength of both the verbal information and the pointing gesture. For example, Thompson and Masaro (1986) presented 3- and 5-year-old children with a ball and a doll and asked them to identify the speaker's referent when she named one object but pointed to the other. In such a situation, pointing and naming are equally strong and children were at chance in their choice between the two objects. However, when making the spoken word ambiguous by manipulating the initial sound $(/ \mathrm{b} /-/ \mathrm{d} /)$, children relied on pointing to resolve reference.

Note that in word learning, children are always faced with an ambiguous verbal referring expression. We therefore replicated Thompson and Masaro's findings for children's interpretations of and learning about novel words (Grassmann \& Tomasello, 2010). For example, in one study, a speaker pointed to a familiar object while saying, 'Let's play with the [novel word]' (a novel object was also on the table) and children chose the pointed-to object (and not the nameless novel object). As stated above, assuming co-reference of pointing and naming is a prerequisite for integrating the two. Thus, relying on pointing in reference resolution of bi-modal acts of reference is crucial for integration. However, true integration requires a second step: resolving the conflict between the known term for the familiar object and the speaker's current use of a word. In the situation at hand, children could, for example, interpret the novel word as a subordinate term for the familiar object. Indeed, in a recent study we found evidence that children not only prefer pointing over labeling, but actually do the second step and learn from seemingly contradictory acts of reference (Grassmann et al., 2011).

Children also rely on a speaker's pointing gesture in order to determine whether a speaker intend to name a whole object versus part of an object (Grassmann \& Tomasello, 2012; Yasuda \& Kobayashi, 2010, but see Markman \& Hansen, 2009). 


\section{Iconic gestures}

Speakers gesture while talking, though a little less when addressing children as compared to when addressing adults (Iverson, Caprici, \& Longobardi, 1999). Gesture reveals important information about speakers' intentions, goals and desires (cf., Kendon, 1994). Mounting evidence (1) indicates strong similarities in the way speech and gesture are processed and (2) suggests that both are integrated in the interpretation of a speaker's communicative intention (cf., Graham \& Kilbreath, 2007; McNeil, 1992; Namy \& Waxman, 1998; Wu \& Coulson, 2007). In adult-child interaction gesturing serves three functions: (1) attracting children's attention, (2) indicating reference to objects, and (3) providing additional information while talking about actions and object functions (Clark \& Estigarribia, 2011).

Children rely on iconic gestures in word learning to disambiguate words for objects, actions, and properties. For example, Goodrich and Hudson-Kam (2009) demonstrated that 2- to 4-year-olds use iconic gesture when disambiguating novel verbs. In this study, children were presented with pairs of novel apparatuses that each had a particular affordance, for example (1) a ramp with a tube in which a puppet could roll down and (2) a spring on which a puppet could sit and bounce. When the speaker produced a novel word and simultaneously performed a gesture that iconically depicted the affordance of one apparatus, toddlers identified the referred-to action / apparatus. At the same age, toddlers also use iconic gestures when learning novel adjectives. For example, a gesture such as the hand motion of squeezing (meaning "spongy") leads to better adjective learning (O’Neill, Topolovec, \& Stern-Cavalcante, 2002).

Children also use iconic gestures when learning nouns (Capone \& McGregor, 2005; Capone, 2012). Interestingly, as compared to learning nouns from pointing only, iconic gestures boost children's word learning and enrich their semantic representation (Capone, 2012). One might be tempted to assume that the improved word learning is a semantic facilitation effect rather than a pragmatic one, since knowledge about the concept related to a novel word is enhanced by the information conveyed in an iconic gesture. However, the semantic effect depends on pragmatic inference, namely, that the verbal or gestural information is relevant to the interpretation of a novel word. Similar enrichment effects can be observed based on information provided verbally (cf., Clark, this volume; Clark \& Grossmann, 1998; Clark \& Wong, 2002).

However, co-speech gestures do not always facilitate word learning. When arbitrary (instead of iconic) gestures are produced together with novel words, toddlers' word learning is compromised (Puccini \& Liszkowski, 2012). This suggests that when a gesture is not informative about a speaker's intended referent, children's attempt to integrate gesture and speech is at its limits and hinders their word learning.

(C) 2014. John Benjamins Publishing Company

All rights reserved 
More research is needed to fully understand the impact of co-speech gesture on word learning. Future research should also address whether and how various aspects of a speaker's gesture and naming, such as the timing in relation to the spoken word, its intonation as well as the number of repetitions, influence children's reference resolution and word learning.

Action, emotion, and intonation

The speaker's current action is also informative about the meaning of a novel word, assuming that verbal behavior is related to action. Booth et al. (2008) found that children learn object labels best when a speaker gazes at and manipulates a named object as compared to only gazing or pointing at it.

Speaker's actions upon a named object not only improve learning, they also influence how a novel word is conceptualized (Hall, Williams, \& Bélanger, 2010; Kobayashi, 1998; Smith, 2005). For example, children use a speaker's action upon a novel part of a novel object in order to determine that he is naming the (acted upon) part rather than the whole (nameless) object (Kobayashi, 1998). Further, Hall, Williams, \& Bélanger (2010) investigated the effect of propertyrelated actions such as squeezing or shaking an object on children's and adults' interpretations of novel words. They found that such actions focus word learners on related object properties in their word interpretation (cf., Smith, 2005 for a similar finding).

In order to establish whether such semantic effects are mediated by pragmatic inferences (about the relevance of the action to the interpretation of the novel word), studies are needed that vary the intentionality of the action. According to pragmatic predictions one would expect that unintentional actions would not alter children's focus on certain object properties in the same way as intentional actions do.

Speaker's actions are particularly important for learning words for actions, which are commonly verbs. In verb learning children focus on intentional action and ignore unintentional behavior (Tomasello \& Barton, 1994; Tomasello, Stosberg, \& Akhtar, 1996), presumably assuming that unintentional actions are not relevant to the conventional verb use/meaning. When differentiating intentional and accidental behaviors in Tomasello and Barton (1994), children probably relied on the adult's non-verbal expression of surprise ('oops') versus satisfaction ('there'). Similarly, when interpreting a novel word in a searching game (Tomasello \& Barton, 1994; Tomasello et al., 1996), children based their reference resolution on the adult's facial and vocal expression of disappointment versus satisfaction. 
Further evidence for children's use of emotions/ expression of affect in word learning comes from a recent study by Berman, Graham, Callaway, and Chambers (2013). In this study children were presented with pairs of objects, one of which was broken and the other enhanced. When the speaker uttered a novel word with sad versus surprised intonation, children correctly inferred which object she was naming. Neither word learning biases nor attention-based accounts to word learning could easily explain such intonational influences on reference resolution.

Unfortunately children's use of intonation and other prosodic speech characteristics have been widely neglected in word learning research. However, they provide important information about the speaker's intentions behind her word use and thus, should be addressed in future research on the pragmatics of word learning.

\section{Context, common ground, and information structure}

Infants as young as 12 months are sensitive to what is given (and established in common ground with the speaker) and what is newly introduced to the interaction (Moll, Koring, Carpenter, \& Tomasello, 2006; Tomasello \& Haberl, 2003) and by 24 months, children use common ground when interpreting novel words (Akhtar, Carpenter, \& Tomasello, 1996; Tomasello \& Akhtar, 1995; Grassmann \& Tomasello; 2007; Grassmann et al., 2009; Grassmann \& Tomasello, 2012).

For example, Tomasello and Akhtar (1995) presented children with a novel word while the speaker demonstrated a novel action with a novel object. Thus, in principle, both the action and the object could be the referent of the novel word. Prior to this naming event, either the action or the object was established in common ground and the other element was thus new to the discourse by the time the novel word was uttered. This manipulation led children to interpret the novel word as referring to the new element by the time the novel word was uttered. We followed up on this study and investigated children's interpretations of novel words in a more natural situation (with an utterance containing both a novel object label as well as a novel action label and sentence accent on the word referring to the new element). In this study, children identified the stressed word with the discourse-new element, at least for object labels (Grassmann \& Tomasello, 2007). This is striking given that research generally establishes that children this young have difficulties interpreting prosodic information structure marking (cf., Ito, this volume).

Importantly, children also are sensitive to what is new from the speaker's perspective and resolve reference correspondingly. That is, when - from the child's perspective - a number of potential referents of a novel word are equally given, children are sensitive to which is new to the speaker and thus must be the referent 
of a novel word used by the speaker (Akhtar et al., 1996). However, Samuelson and Smith (1998) argued that children might assign merely because those very objects were simply more salient and drew children's attention (because they had been treated differently compared to the other objects; cf., Horst, Samuelson, Kucker, \& McMurray, 2011). Indeed, Samuelson and Smith (1998) demonstrated that in a situation where an object was treated distinctively (by introducing it at another place) children also associated a novel word to this very object. However, Diesendruck, Markson, Akhtar, and Reudor (2004) countered providing evidence that special treatment is not enough for children to conclude that a speaker intends to refer to it. Rather, a clear expression of her intention to treat an object in a distinctive way is required.

All this suggests that taking common ground (i.e., given information) versus new information into account when interpreting novel words is indeed a pragmatic inference and can not be attributed to mere response to saliency. However, the question is what inferences children draw exactly. The literature provides two alternative pragmatic accounts that both rely on exclusion inferences (cf., Grassmann, 2013). Either children assume that people are excited about new things (and thus upon hearing someone excitedly uttering a novel word, exclude everything that is old news, cf., Akhtar et al., 1996; Grassmann et al., 2009), or children might expect speakers to provide names for jointly attended objects more or less immediately (and thus upon hearing a novel word and seeing a number of potential referents, they exclude all the objects that are established in common ground but not named, cf. Nilsen et al., 2008). Future research is necessary to determine the contribution of both expectations to children's use of what is given and what is new in word learning. In a recent study, we addressed this question. We demonstrated that children use the speaker's gesture and intonation in order to determine whether she is referring to something that is established in common ground or to something else (Grassmann \& Tomasello, 2012). The findings speak against an 'immediate naming' expectation.

\section{Contrast and conventionality}

A well-known phenomena in word learning is that children exclude familiar objects as referents for novel words (e.g., Vincent-Smith, Bricker, \& Bricker, 1974; Markman \& Wachtel, 1988). According to a pragmatic account of word learning, such exclusion rests on the expectation of conventional object labels for familiar objects (cf. Clark, 1990; Diesendruck \& Patael, in press; Gathercole, 1989; Grassmann, 2013; Clark, this volume). Alternative accounts maintain either that children adhere to word learning biases such as the mutual exclusivity bias (Markman, 1989; Markman \& Wachtel, 1988; Merriman \& Bowman, 1989) or that 
novel objects are salient candidate referents for novel words (Golinkoff et al., 1992; Mathner \& Plunkett, 2012).

Mounting evidence supports the pragmatic explanation of word learning by exclusion. First, a number of studies demonstrate that exclusion is not restricted to children's interpretation of novel words but also applies to more complex verbal expressions (Diesendruck \& Markson, 2001; Scofield \& Behrend, 2007). Second, the exclusion of objects that are established in common ground as referents of novel words is logically similar to exclusion of familiar objects as referents of novel words (cf., Grassmann et al., 2009; Grassmann, 2013). Third, children do not blindly exclude familiar objects as referents of novel words; they do so only when they can (rationally) expect a speaker to use a certain expression for a familiar object. For example, when a speaker does not speak a certain language or has a history of unconventional language use, children do not seem to exclude any of the available objects as potential referents of the speaker's utterance (Diesendruck, 2005; Diesendruck, Carmel, \& Markson, 2010; Diesendruck \& Markson, 2001; Grassmann, Schreiner, \& Tomasello, 2011; Sobel, Sedivy, Buchanan, \& Hennessy, 2011). Forth, exclusion is facilitated when the speaker's gaze, gestures, and/or language provides converging evidence (Graham et al., 2010; Saylor, Sabbagh, \& Baldwin, 2002).

Thus, overall, children's exclusion of certain entities in word learning appears to be based on specific expectations of conventional or otherwise agreed-upon referring expressions and the mismatch with what a speaker really said (cf., Clark, 1990; Diesendruck \& Markson, 2001; Gathercole, 1989; Grassmann, 2013). Nevertheless, the theoretical debate around the question of whether exclusion in word learning is due to children's sophisticated pragmatic inferences about speakers' intentions or based on a priori word learning biases/ heuristics continues. The problem is that any account is difficult to falsify. However, for non-pragmatic accounts it is unclear how they would explain that children avoid pragmatically infelicitous exclusions. As a challenge to pragmatic accounts it has been put forward that even 10-month-olds prefer novel objects over familiar ones as referents of novel words (Mathner \& Plunkett, 2010), and that individuals with socialpragmatic impairments exclude familiar objects as referents of novel words (and facts, e.g., de Marchena, Eigsti,Worek, Ono, \& Snedeker, 2011; Preissler \& Carey, 2005). But this does not suggest that pragmatics are irrelevant to word learning by exclusion, nor does blocking of infelicitous exclusion mean that exclusion is always pragmatic. Rather, the empirical evidence seems to suggest that there must be multiple ways to exclusion, some pragmatic, others not.

In favor of the pragmatic account, it can be argued that the social-pragmatic and intention-reading skills of very young infants and individuals with ASD have been underestimated (cf., Kovács, Téglás, \& Endress, 2010; Luyster \& Lord, 2009) 
and thus, potentially, these individuals actually do engage in pragmatic inferences when excluding familiar objects as referents of novel words. However, the pragmatic account of exclusion probably is at its limits when explaining exclusion in individuals with severe retardation (McIlvane \& Stoddard, 1981) and animals (Aust; Range, Steurer, \& Huber, 2008; Kaminski, Call, \& Fisher, 2004; Pepperberg \& Wilcox, 2000; see Wilkinson, Duwe, \& McIlvane, 1998 for a review). Thus, it appears, it is evident that pragmatic expectations about language use are not a prerequisite for exclusion (cf., Grassmann, 2013), yet, pragmatic inferences obviously are at work when infelicitous exclusion is avoided.

The speaker's verbal behavior: Sentence frame, discourse topic, and the speaker's reliability

The verbal information that is provided together with novel words plays an important role in children's interpretation of novel words (cf., Callanan, this volume, Clark, this volume). Such information is pragmatic, (1) because it is part of the speaker's expression of a certain communicative intention and (2) because it contains relevant information about the conventional use of words.

Together with a novel word, caretakers provide (and children use) information about how novel words relate to and contrast with known words (Clark \& Grossmann, 1998; Clark \& Wong, 2002; Saylor et al., 2002). For example, when the speaker explicitly expresses the contrast between a known word (e.g., dog) and a novel word (e.g., paw), by saying, See this dog. This is his paw children are more likely to exclude familiar objects as the referents than they are if no such explicit contrast is made (Saylor et al., 2002; see O’Hanlon \& Robertson, 2007 on adjective learning and explicit contrast).

When using a novel word, a speaker might also explicitly state that she is unsure whether she is using the correct object label. In such a situation, children avoid learning the (potentially) erroneous word (Sabbagh \& Baldwin, 2001; Callanan, this volume). When a speaker experiences difficulties naming an object and producing disfluencies ( $u m, e h$ ), children seem to assume that she must be referring to a novel object which she had not previously mentioned (Kidd, White, \& Aslin, 2011).

The wording and structure of the utterance that contains a novel word also guides children's interpretations. For example, children exclude objects as likely referents of a speaker's communicative act when a wh-word and rising intonation is used (where is the nurmo?, Nurmsoo \& Bloom, 2008). But, children learn words equally well from different sentential frames, expressing different intentions (e.g., requesting versus naming, Callanan, Akhtar \& Sussmann (2012), cited in Callanan, this volume). 
The discourse topic established verbally prior to the utterance of a novel word also guides children's word interpretation. For example, when a child and a speaker have been discussing the shapes of various objects prior to the use of a novel adjective, then the child tends to interpret the novel adjective as referring to a (novel) shape. In contrast, when the discourse is about textures, the child relates the adjective to the texture of the novel object (Akhtar, 2002). Further, when a speaker states her preference for one toy without naming it, I really like playing with this toy, the child interprets a novel word that the experimenter uses later when requesting an object as the name of the preferred object (Saylor \& Troseth, 2006; Saylor, Sabbagh, Fortuna \& Troseth, 2009).

The speaker's knowledge state: Reliability, ignorance and false beliefs

The speaker's verbal behavior prior to his use of a novel word also provides important information whether the speaker is a reliable and conventional language user or not. Importantly, children block learning novel words from unreliable and unconventional language users (Birch, Vauthier, \& Bloom, 2008; Diesendruck et al., 2010; Jaswal \& Neely, 2006; Koenig \& Harris, 2005; Koenig \& Woodward, 2010; Sabbagh \& Shafman, 2009; Scofield \& Behrend, 2008; Sobel \& Corriveau, 2010; Sobel et al., 2011).

Further evidence for children's assessment and use of the speaker's knowledge state in word learning is their interpretation of novel words in a situation when a speaker has a false belief about the whereabouts of novel objects; children as young as 17 months of age interpret novel words in accordance with the speaker's beliefs rather than her non-verbal reference. For example, when an object's location (say in one of two opaque buckets) is changed while the child is looking but without the speaker's knowledge, and later a speaker produces a novel word while indicating a location, children (correctly) associate the speaker's novel word with the object that was originally at the location rather than with another object that currently is in that location (Carpenter, Call, \& Tomasello, 2002; Houston-Price et al., 2011).

Children's use of speakers' knowledge states, such as false belief and ignorance, offers the strongest evidence for their reliance on speakers' intentions in word learning. First, it suggests that children are aware of the importance of intentions for word use and meaning. Second, children's blocking of inferences about word meaning and their avoidance of learning from unreliable and ignorant speakers suggests that they want to learn conventional language and not just any soundreferent mapping. 


\section{Current debates and future research}

Word learning researchers debate (1) whether phenomena such as those reviewed in this chapter are truly pragmatic or could (and should) be explained by other, less cognitively taxing processes and (2) how children weight pragmatic information in comparison to other information, specifically, low-level attentional processes or word learning biases. Some aspects of these debates were outlined throughout the chapter.

How to weight associative learning versus pragmatic information in word learning?

A potential challenge for pragmatic accounts that has not yet been addressed is that infants as young as 6-9 months seem to know some words and look at objects corresponding to words (Bergelson \& Swingley, 2012). Such early word knowledge might be mere word-object associations, given that before 18 months of age infants heavily rely on such processes and ignore pragmatic information (e.g., Hollich et al., 2000). But does the fact that novice word learners depend on low-level processes when forming word-object associations really challenge social pragmatic approaches to word learning? I would argue that early associative learning is not what makes children's word learning so special and interesting (even some animals master that, cf. Pepperberg \& Wilcox, 2000; Kaminski et al., 2004). The fascinating thing about children's word learning is that they go beyond mere forming associations when learning words. Language use and communicative intentions become pivotal and outweigh associative word learning during the second year of life. This is what is intriguing, and one of the major questions for future research is to explain how this transition proceeds (e.g., Golinkoff \& Hirsh-Pasek, 2006).

Importantly, social-pragmatic word learning mechanisms do not merely replace associative ones, but word knowledge stemming from situations that involved understanding speakers' intentions is mentally represented and processed differently as compared to word knowledge that was established associatively by contingency learning. For example, children build only fragile and short-lived word knowledge based on temporal contingency. In contrast, children build stronger (seemingly semantic) representation for words that they learned in social interaction and from reading a speaker's intention (e.g., Koenig \& Woodward, 2011; Sabbagh \& Shafman, 2009). Bannard and Tomasello (2012) show that children are only able to point to referents of newly learned words when they were learned in joint attentional interaction. For words that were learned 
outside of joint attention (but associated with an object the child happened to be attending to), no subsequent communicative use was found - although looking measures indicated an association between word form and object had been made. In addition, Hirotani, Stets, Striano, and Friederici (2009) report that only words learned during social interaction seem to be stored in the mental lexicon and violations of such word-concept pairs elicit brain activation linked to semantic processing (i.e. N400). For word-referent pairs that were learned by association only, no such brain activity was found.

Thus, in sum, human brains learn and processes words differently depending on how they were learned. Truly knowing a word includes knowing how a word is used. Thus, truly learning a word also requires learning how the word is used and since humans act intentionally, identifying a speaker's intentions underlying word use is pivotal to learning the word (see Diesendruck \& Patael, in press for a similar argument).

Future research needs to establish how children develop the ability to read and interpret other's intentions (in word learning) and identify the role observations play in learning how communicative acts relate to contexts (in which some aspects are naturally salient and attract caretakers' as well as children's attention). The Emergentist Coalition Model (Hollich et al., 2000) is a valuable framework for this enterprise. Indeed, recent theoretical, experimental and computational work has explored the possibility that word learning heuristics could be acquired as a result of children's early experiences with words. Specifically, repeated exposure to words being used in particular ways (e.g. conventionally and contrastively) might reveal to the child the utility of adopting certain heuristics when they encounter further new words (e.g. Byers-Heinlein \& Werker, 2009; Gogate \& Hollich, 2010; Houston-Price, Caloghiris, \& Raviglione, 2010; Callanan, this volume).

What are children learning when learning a word?

Most contemporary approaches to word learning (implicitly) portray it as a process of mapping words to concepts (cf., Golinkoff et al., 2000; Hall \& Waxman, 2004). If word learning is understood this way, then, naturally, pragmatic information is only one of several means to establish such mappings - and, depending on one's beliefs and the current state of the art of word learning research, one might assign more or less importance to pragmatic information. In contrast, radically pragmatic, that is usage-based, accounts of word and language learning go beyond merely stating that children are attuned to and primarily attend to social cues when resolving the speaker's intentions and interpreting novel words (cf. Diesendruck \& Patael, in press; Nelson, 1985; Tomasello, 2003). In the 
framework of social-pragmatic approaches to word learning, researchers must move beyond prioritizing social-pragmatic information in reference resolution and take Wittgenstein's usage-based theory of meaning more seriously: words and sentences have no meaning beyond their use. Knowing the meaning of a word is nothing but knowing how to use it (cf., Wittgenstein, 1953). Learning a word, thus, means learning how it is used in communication, not (merely) what concept it stands for.

On purely logical grounds, usage-based accounts imply that there is no other way than observing the pragmatics (that is, the contexts and the speakers' intentions) of word use in order to understand and correctly learn any word. In addition, any usage-based account implies that a first encounter with (and interpretation of) a novel word is just the beginning of learning the rules of its use. Accordingly, one would expect two things: (1) that individuals differ with respect to the exact meaning of any word in their vocabularies, and (2) that after first encountering a word, word meaning further develops depending on an individual's experience (cf. Clark, this volume). Future research on the pragmatics of word learning, therefore, should move beyond reference resolution, retention and spontaneous extension, and investigate children's developing word knowledge and the role pragmatic information plays in the further development of word meaning and the full acquisition of conventional word use.

\section{References}

Akhtar, N. (2002). Relevance and early word learning. Journal of Child Language, 29, 677-686. DOI: $10.1017 / \mathrm{S} 0305000902005214$

Akhtar, N., Carpenter, M., \& Tomasello, M. (1996). The role of discourse novelty in early word learning. Child Development, 67, 635-645. DOI: 10.2307/1131837

Akhtar, N. \& Tomasello, M. (1996). Two-year-olds learn words for absent objects and actions. British Journal of Developmental Psychology, 14, 79-93. DOI: 10.1111/j.2044-835X.1996. tb00695.x

Akhtar, N., \& Tomasello, M. (2000). The social nature of words and word learning. In R. M. Golinkoff \& K. Hirsh-Pasek (Eds.), Becoming a Word Learner: A Debate on Lexical Acquisition (pp. 115-135). Oxford: OUP. DOI: 10.1093/acprof:oso/9780195130324.003.005

Aust, U., Range, F., Steurer, M., \& Huber, L. (2008). Inferential reasoning by exclusion in pigeons, dogs, and humans. Animal Cognition, 11, 587-597. DOI: 10.1007/s10071-008-0149-0

Bakeman, R., \& Adamson, L.B. (1984). Coordinating attention to people and objects in mother-infant and peer-infant interaction. Child Development, 55, 1278-1289. DOI: $10.2307 / 1129997$

Baldwin, D. A. (1991). Infants' contribution to the achievement of joint reference. Child Development, 62, 875. DOI: $10.2307 / 1131140$ 
Baldwin, D. A. (1993). Infants ability to consult the speaker for clues to word reference. Journal of Child Language, 20, 395-418. DOI: 10.1017/S0305000900008345

Baldwin, D. A., Markman, E. M., Bill, B., Desjardins, R.N., Irwin, J. M., \& Tidball, G. (1996). Infants' reliance on a social criterion for establishing word-object relations. Child Development, 67, 3135-3153. DOI: 10.2307/1131771

Bannard, C., \& Tomasello, M. (2012). Can we dissociate contingency learning from social learning in word acquisition by 24-month-olds? PLoS ONE, 7(11), e49881. DOI: 10.1371/journal. pone.0049881

Baron-Cohen, S., Baldwin, D. A., \& Crowson, M. (1997). Do children with autism use the speaker's direction of gaze strategy to crack the code of language? Child Development, 68, 48-57. DOI: $10.2307 / 1131924$

Bergelson, E., \& Swingley, D. (2012). At 6-9 months, human infants know the meanings of many common nouns. Proceedings of the National Academy of Sciences, 109, 3253-3258. DOI: 10.1371/journal.pone.0049881

Berman, J. M. J., Graham, S. A., Callaway, D., \& Chambers, C. G. (2013). Preschoolers use emotion in speech to learn new words. Child Development, 84(5), 1791-1805. DOI: 10.1111/ cdev. 12074

Birch, S. A. J., S. A. Vauthier, \& P. Bloom. 2008. Three- and four-year-olds spontaneously use others' past performance to guide their learning. Cognition, 107, 1018-1034. DOI: 10.1016/j. cognition.2007.12.008

Booth, A.E., McGregor, K. K., \& Rohlfing, K. J. (2008). Socio-pragmatics and attention: Contributions to gesturally guided word learning in toddlers. Language Learning and Development, 4, 179-202. DOI: 10.1080/15475440802143091

Brand, R. J. (2000). Learning novel nouns: Children use mulitple cues. Monographs of the Society for Research in Child Development, 65, 41-61. DOI: 10.1111/1540-5834.00094

Briganti, A. M., \& Cohen, L. B. (2011). Examining the role of social cues in early word learning. Infant Behavior and Development, 34, 211-214. DOI: 10.1016/j.infbeh.2010.12.012

Brooks, R., \& Meltzoff, A.N. (2008). Infant gaze following and pointing predict accelerated vocabulary growth through two years of age: A longitudinal, growth curve modeling study. Journal of Child Language, 35(1), 207-220. DOI: 10.1017/S030500090700829X

Byers-Heinlein, K., \& Werker, J. F. (2009). Monolingual, bilingual, trilingual: Infants' language experience influences the development of a word-learning heuristic. Developmental Science, 12, 815-823. DOI: 10.1111/j.1467-7687.2009.00902.x

Capone, N.C. (2012). Can semantic enrichment lead to naming in a word extension task? American Journal of Speech-Language Pathology, 21, 279-292. DOI: 10.1044/1058-0360(2012/11-0019)

Capone, N.C., \& McGregor, K. K. (2005). The effect of semantic representation on toddlers' word retrieval. Journal of Speech, Language, and Hearing Research, 48, 1468-1480. DOI: $10.1044 / 1092-4388(2005 / 102)$

Carpenter, M., Call, J., \& Tomasello, M. (2002). A new false belief test for 36-month-olds. British Journal of Developmental Psychology, 20(3), 393-420. DOI: 10.1348/026151002320620316

Clark, E. V. (1990). On the pragmatics of contrast. Journal of Child Language, 17, 417-431. DOI: $10.1017 /$ S0305000900013842

Clark, E. V., \& Estigarribia, B. (2011). Using speech and gesture to introduce new objects to young children. Gesture, 11, 1-23. DOI: 10.1075/gest.11.1.01cla

Clark, E. V., \& Grossman, J. B. (1998). Pragmatic directions and children's word learning. Journal of Child Language, 25, 1-18. DOI: 10.1017/S0305000997003309 
Clark, E. V.C. \& Wong, A.D. (2002). Pragmatic directions about language use: Offers of words and relations. Language in Society, 31(2), 181-212.

de Marchena, A., Eigsti, I.-M., Worek, A., Ono, K.E., \& Snedeker, J. (2011). Mutual exclusivity in autism spectrum disorders: Testing the pragmatic hypothesis. Cognition, 119, 96-113. DOI: $10.1016 /$ j.cognition.2010.12.011

Diesendruck, G. (2005). The principles of conventionality and contrast in word learning: An empirical examination. Developmental Psychology, 41, 451-463. DOI: 10.1037/0012-1649.41.3.451

Diesendruck, G., \& Markson, L. (2001). Children's avoidance of lexical overlap: A pragmatic account. Developmental Psychology, 37, 630-641. DOI: 10.1037/0012-1649.37.5.630

Diesendruck, G., Carmel, N., \& Markson, L. (2010). Children's sensitivity to the conventionality of sources. Child Development, 81, 652-668. DOI: 10.1111/j.1467-8624.2009.01421.x

Diesendruck, G., Markson, L., Akhtar, N., \& Reudor, A. (2004). Two-year-olds' sensitivity to speakers' intent: An alternative account of Samuelson and Smith. Developmental Science, 7, 33-41. DOI: 10.1111/j.1467-7687.2004.00320.x

Diesendruck, G. \& Patael, S. (in press). The pragmatics of disambiguation. In T. Matsui (Ed.), Pragmatics and Theory of Mind. Amsterdam: John Benjamins.

Gathercole, V.C. (1989). Contrast: A semantic constraint? Journal of Child Language, 16, 685-702. DOI: $10.1017 /$ S0305000900010795

Gliga, T., \& Csibra, G. (2009). One-year-old infants appreciate the referential nature of deictic gestures and words. Psychological Science, 20, 347-353. DOI: 10.1111/j.1467-9280.2009.02295.x

Gogate, L. J., \& Hollich, G. (2010). Invariance detection within an interactive system: A perceptual gateway to language development. Psychological Review, 117, 496-516. DOI: 10.1037/ a0019049

Golinkoff, R., \& Hirsh-Pasek, K. (2006). Baby wordsmith. From associationist to social sophisticate. Current Directions in Psychological Science, 15, 30-33. DOI: 10.1111/j.0963-7214.2006.00401.x

Golinkoff, R. M., Hirsh-Pasek, K., Bailey, L.M. \& Wenger, N. R. (1992). Young children and adults use lexical principles to learn new nouns. Developmental Psychology, 28, 99-108. DOI: 10.1037/0012-1649.28.1.99

Golinkoff, R.M., Hirsh-Pasek, K., Bloom, L., Smith, L., Woodward, A., \& Akhtar, N., et al. (Eds.) (2000). Becoming a Word Learner. Oxford: OUP. DOI: 10.1093/acprof: oso/9780195130324.001.0001

Golinkoff, R., Mervis, C. B., \& Hirsh-Pasek, K. (1994). Early object labels - the case for a developmental lexical principles framework. Journal of Child Language, 21, 125-155. DOI: $10.1017 /$ S0305000900008692

Goodrich, W., \& Hudson Kam, C. L. (2009). Co-speech gesture as input in verb learning. Developmental Science, 12, 81-87. DOI: 10.1111/j.1467-7687.2008.00735.x

Graham, S.A., \& Kilbreath, C.S. (2007). It's a sign of the kind: Gestures and words guide infants' inductive inferences. Developmental Psychology, 43, 1111-1123. DOI: 10.1037/0012-1649.43.5.1111

Graham, S. A., Nilsen, E. S., Collins, S., \& Olineck, K. (2010). The role of gaze direction and mutual exclusivity in guiding 24-month-olds' word mappings. British Journal of Developmental Psychology, 28, 449-465. DOI: 10.1348/026151009X424565

Grassmann, S. (2013). Word learning by exclusion: The role of specific naming expectations. In F. Liedtke \& C. Schulze, Beyond the Words. Content, Context, and Inference (pp. 67-89). Berlin: De Gruyter Mouton. 
Grassmann, S., \& Tomasello, M. (2007). Two-year-olds use primary sentence accent to learn new words. Journal of Child Language, 34, 677. DOI: 10.1017/S0305000907008021

Grassmann, S., \& Tomasello, M. (2009). Young children follow pointing over words in interpreting acts of reference. Developmental Science, 13, 252-263. DOI: 10.1111/j.1467-7687.2009.00871.x

Grassmann, S., \& Tomasello, M. (2012). Gesture juxtaposition and sentence accent in part term learning. Poster presented at the ISSBD, Edmonton, Canada.

Grassmann, S., Lenke, J., \& Tomasello, M. (2011). Children's understanding of anaphoric reference. Paper presented at the IASCL Triennial Meeting, Montreal, Canada.

Grassmann, S., Magister, C., \& Tomasello, M. (2011). What children do when pointing and naming conflict. Paper presented at the SRCD Biennial Meeting, Montreal, Canada.

Grassmann, S., Schreiner, M., \& Tomasello, M. (2011). The pragmatics of exclusion: Children exclude familiar objects as referents of applicable known super-ordinate terms. Paper presented at the XPrag Conference, Barcelona, Spain.

Grassmann, S., Stracke, M., \& Tomasello, M. (2009). Two-year-olds exclude novel objects as potential referents of novel words based on pragmatics. Cognition, 112, 488-493. DOI: 10.1016/j.cognition.2009.06.010

Hall, D. G., \& Waxman, S. R. (Eds.) (2004). Weaving a Lexicon. Cambridge, MA: The MIT Press.

Hall, D. G., Williams, S. G., \& Bélanger, J. (2010). Learning Count Nouns and Adjectives: Understanding the Contributions of Lexical Form Class and Social-Pragmatic Cues. Journal of Cognition and Development, 11(1), 86-120. doi:10.1080/15248370903453592

Hansen, M. B., \& Markman, E. M. (2009). Children's use of mutual exclusivity to learn labels for parts of objects. Developmental psychology, 45, 592-6.

Hennon, E., Chung, H.L., \& Brown, E. (2000). What does it take for 12-month-olds to learn a word? Monographs of the Society for Research in Child Development, 65,

Hirotani, M., Stets, M., Striano, T., \& Friederici, A. D. (2009). Joint attention helps infants learn new words: Event-related potential evidence. NeuroReport, 20, 600-605. DOI: 10.1097/ WNR.0b013e32832a0a7c

Hollich, G. J., Hirsh-Pasek, K., Golinkoff, R. M., Brand, R. J., Brown, E., Chung, H. L. \& Hennon, E. (2000). Breaking the language barrier: An emergentist coalition model for the origins of word learning. Monographs of the Society for Research in Child Development, 65.

Horst, J.S., Samuelson, L. K., Kucker, S.C., \& McMurray, B. (2011). What's new? Children prefer novelty in referent selection. Cognition, 118(2), 234-244. DOI: 10.1016/j. cognition.2010.10.015

Houston-Price, C., Caloghiris, Z., \& Raviglione, E. (2010). Language experience shapes the development of the mutual exclusivity bias. Infancy, 15, 125-150. DOI: 10.1111/j.1532-7078.2009.00009.x

Houston-Price, C., Plunkett, K., \& Duffy, H. (2006). The use of social and salience cues in early word learning. Journal of Experimental Child Psychology, 95, 27-55. DOI: 10.1016/j. jecp.2006.03.006

Houston-Price, C., Goddard, K., Séclier, C., Grant, S. C., Reid, C. J. B., Boyden, L. E., \& Williams, R. (2011). Tracking speakers' false beliefs: Is theory of mind available earlier for word learning? Developmental Science, 14, 623-634. DOI: 10.1111/j.1467-7687.2010.01003.x

Iverson, J. M., Capirci, O., Longobardi, E., \& Cristina Caselli, M. (1999). Gesturing in motherchild interactions. Cognitive Development, 14, 57-75. DOI: 10.1016/S0885-2014(99)80018-5 
Jaswal, V.K., \& Hansen, M. B. (2006). Learning words: Children disregard some pragmatic information that conflicts with mutual exclusivity. Developmental Science, 9, 158-165. DOI: 10.1111/j.1467-7687.2006.00475.x

Jaswal, V.K. (2010). Explaining the disambiguation effect: Don't exclude mutual exclusivity. Journal of Child Language, 37, 95-113. DOI: 10.1017/S0305000909009519

Jaswal, V.K., \& Neely, L.A. 2006. Adults don't always know best: Preschoolers use past reliability over age when learning new words. Psychological Science, 17, 757-758. DOI: 10.1111/j.1467-9280.2006.01778.x

Kaminski, J., Call, J., \& Fischer, J. (2004). Word learning in a domestic dog: Evidence for fast mapping. Science, 304, 1682-1683. DOI: 10.1126/science.1097859

Kendon, A. (1994). Do gestures communicate? A review. Research on Language and Social Interaction, 27, 175-200. DOI: 10.1207/s15327973rlsi2703_2

Kidd, C., White, K.S., \& Aslin, R.N. (2011). Toddlers use speech disfluencies to predict speakers' referential intentions. Developmental Science, 14, 925-934. DOI: 10.1111/j.1467-7687.2011.01049.x

Kobayashi, H. (1998). How 2-year-old children learn novel part names of unfamiliar objects. Cognition, 68, B41-B51. DOI: 10.1016/S0010-0277(98)00044-4

Koenig, M.A., \& Harris, P. L. (2005). Preschoolers mistrust ignorant and inaccurate speakers. Child Development, 76, 1261-77. DOI: 10.1111/j.1467-8624.2005.00849.x

Koenig, M. A., \& Woodward, A. L. (2010). Sensitivity of 24-month-olds to the prior inaccuracy of the source: Possible mechanisms. Developmental Psychology, 46, 815-826. DOI: 10.1037/ a0019664

Koenig, M., \& Woodward, A.L. (2011). Toddlers learn words in a foreign language: The role of native vocabulary knowledge. Journal of Child Language, 39, 322-337. DOI: 10.1017/ S0305000911000067

Kovács, Á. M., Téglás, E. \& Endress, A. D. (2010). The social sense: Susceptibility to others' beliefs in human infants and adults. Science, 330, 1830-1834. DOI: 10.1126/science.1190792

Liebal, K., Behne, T., Carpenter, M., \& Tomasello, M. (2009). Infants use shared experience to interpret pointing gestures. Developmental Science, 12, 264-271. DOI: 10.1111/j.1467-7687.2008.00758.x

Luyster, R., \& Lord, C. (2009). Word learning in children with autism spectrum disorders. Developmental Psychology, 45, 1774-1786. DOI: 10.1037/a0016223

Mather, E., \& Plunkett, K. (2010). Novel labels support ten-month-olds' attention to novel objects. In K. Franich, K. M. Iserman, \& L.L. Keil (Eds.) Proceedings of the 34th Annual Boston University Conference on Language Development (pp. 303-314). Somerville, MA: Cascadilla Press.

Markman, E. M. (1989). Categorization and Naming in Children: Problems of Induction. Cambridge, MA: The MIT Press.

Markman, E. M., \& Wachtel, G. F. (1988). Children's use of mutual exclusivity to constrain the meanings of words. Cognitive Psychology, 20, 121-157. DOI: 10.1016/0010-0285(88)90017-5

Mather, E., \& Plunkett, K. (2012). The role of novelty in early word learning. Cognitive science, $36,1157-77$.

McIlvane, W. J., \& Stoddard, T. (1981). Acquisition of matching-to-sample performances in severe retardation: learning by exclusion. Journal of mental Deficiency Research, 25, 33-48.

McNeill, D. (1992). Hand and Mind: What Gestures Reveal about Thought. Chicago IL: University of Chicago Press. 
Merriman, W.E., \& Bowman, L. L. (1989). The mutual exclusivity bias in children's word learning. Monographs of the Society for Research in Child Development, 54(serial no. 220). DOI: $10.2307 / 1166130$

Moll, H., Koring, C., Carpenter, M., \& Tomasello, M. (2006). Infants determine others' focus of attention by pragmatics and exclusion. Journal of Cognition and Development, 7, 411-430. DOI: 10.1207/s15327647jcd0703_9

Moore, C., Angelopoulos, M., \& Bennett, P. (1999). Word learning in the context of referential and salience cues. Developmental Psychology, 35, 60-68. DOI: 10.1037/0012-1649.35.1.60

Namy, L.L., \& Waxman, S.R. (1998). Words and gestures: Infants' interpretations of different forms of symbolic reference. Child Development, 69, 295-308.

Nelson, K. (1985). Making Sense. The Acquisition of Shared Meaning. New York, NY: Academic press.

Nilsen, E. S., Graham, S. A., \& Pettigrew, T. (2008). Preschoolers' word mapping: The interplay between labelling context and specificity of speaker information. Journal of Child Language, 36, 673. DOI: $10.1017 /$ S0305000908009021

Nurmsoo, E., \& Bloom, P. (2008). Preschoolers' perspective taking in word learning: Do they blindly follow eye gaze? Psychological Science, 19, 211-215. DOI: 10.1111/j.1467-9280.2008.02069.x

O'Hanlon, C. G., \& Roberson, D. (2007). What constrains children's learning of novel shape terms? Journal of Experimental Child Psychology, 97, 138-148. DOI: 10.1016/j. jecp.2006.12.002

O’Neill, D. K., Topolovec, J., \& Stern-Cavalcante, W. (2002). Feeling sponginess: The importance of descriptive gestures in 2- and 3-year-old children's acquisition of adjectives. Journal of Cognition and Development, 3, 243-277. DOI: 10.1207/S15327647JCD0303_1

Pepperberg, I. M., \& Wilcox, S. E. (2000). Evidence for a form of mutual exclusivity during label acquisition by grey parrots (Psittacus erithacus)? Journal of Comparative Psychology, 114, 219-231. DOI: 10.1037/0735-7036.114.3.219

Preissler, M. A., \& Carey, S. (2005). The role of inferences about referential intent in word learning: Evidence from autism. Cognition, 97, B13-B23. DOI: 10.1016/j.cognition.2005.01.008

Pruden, S. M., Hirsh-Pasek, K., Golinkoff, R. M., \& Hennon, E. A. (2006). The birth of words: Ten-month-olds learn words through perceptual salience. Child Development, 77, 266-280. DOI: $10.1111 /$ j.1467-8624.2006.00869.x

Puccini, D. \& Liszkowski, U. (2012). 15-month-old infants fast map words but not representational gestures of multimodal labels. Front. Psychology, 3. DOI: 10.3389/fpsyg.2012.00101

Sabbagh, M. A., \& Baldwin, D. A. (2001). Learning words from knowledgeable versus ignorant speakers: Links between preschoolers' theory of mind and semantic development. Child Development, 72, 1054-1070. DOI: 10.1111/1467-8624.00334

Sabbagh, M.A., \& Shafman, D. (2009). How children block learning from ignorant speakers. Cognition, 112, 415-22. DOI: 10.1016/j.cognition.2009.06.005

Samuelson, L. K., \& Smith, L. B. (1998). Memory and attention make smart word learning: An alternative account of Akhtar, Carpenter, and Tomasello. Child Development, 69, 94-104.

Saylor, M., \& Troseth, G. (2006). Preschoolers use information about speakers' desires to learn words. Cognitive Development, 21, 214-231. DOI: 10.1016/j.cogdev.2006.03.006

Saylor, M. M., Sabbagh, M. A., \& Baldwin, D. A. (2002). Children use whole-part juxtaposition as a pragmatic cue to word meaning. Developmental Psychology, 38, 993-1003. DOI: $10.1037 / 0012-1649.38 .6 .993$ 
Saylor, M. M., Sabbagh, M. A., Fortuna, A., \& Troseth, G. (2009). Preschoolers use speakers' preferences to learn words. Cognitive Development, 24, 125-132. DOI: 10.1016/j. cogdev.2008.12.003

Scofield, J., \& Behrend, D. A. (2007). Two-year-olds differentially disambiguate novel words and facts. Journal of Child Language, 34, 875-889. DOI: 10.1017/S0305000907008100

Scofield, J., \& Behrend, D. A. 2008. Learning words from reliable and unreliable speakers. Cognitive Development, 23, 278-290. DOI: 10.1016/j.cogdev.2008.01.003

Smith, L. (2000). Learning how to learn words: An associative crane. In. R. M. Golinkoff, K. Hirsh-Pasek, L. Bloom, L. B. Smith, A.L. Woodard, N. Akhtar, M. Tomasello, \& G. Hollich (Eds.), Becoming a Word Learner: A Debate on Lexical Acquisition (pp. 51-80). Oxford: OUP. DOI: 10.1093/acprof:oso/9780195130324.003.003

Smith, L. B. (2005). Action alters shape categories. Cognitive Science, 29, 665-679. DOI: 10.1207/ s15516709cog0000_13

Sobel, D. M., \& Corriveau, K.H. (2010). Children monitor individuals' expertise for word learning. Child Development, 81, 669-679. DOI: 10.1111/j.1467-8624.2009.01422.x

Sobel, D. M., Sedivy, J., Buchanan, D. W., \& Hennessy, R. (2011). Speaker reliability in preschoolers' inferences about the meanings of novel words. Journal of Child Language, 39, 90-104. DOI: $10.1017 /$ S0305000911000018

Thompson, L. A., \& Massaro, D. W. (1986). Evaluation and integration of speech and pointing gestures during referential understanding. Journal of Experimental Child Psychology, 42, 144-168. DOI: 10.1016/0022-0965(86)90020-2

Thompson, L.A., \& Massaro, D. W. (1994). Children's integration of speech and pointing gestures in comprehension. Journal of Experimental Child Psychology, 57, 327-354. DOI: 10.1006/jecp.1994.1016

Tomasello, M. (2003). Constructing a Language: A Usage-based Theory of Language Acquisition. Harvard, MA: Harvard University Press.

Tomasello, M., \& Akhtar, N. (1995). Two-year-olds use pragmatic cues to differentiate reference to objects and actions. Cognitive Development, 10, 201-224. DOI: 10.1016/0885-2014(95)90009-8

Tomasello, M., \& Barton, M.E. (1994). Learning words in nonostensive contexts. Developmental Psychology, 30, 639-650. DOI: 10.1037/0012-1649.30.5.639

Tomasello, M., \& Farrar, J.M. (1986). Joint attention and early language. Child Development, 57, 1454-1463. DOI: $10.2307 / 1130423$

Tomasello, M. \& Haberl, K. (2003). Understanding attention: 12- and 18-month-olds know what's new for other persons. Developmental Psychology, 39, 906-912. DOI: 10.1037/0012-1649.39.5.906

Tomasello, M., Strosberg, R., \& Akhtar, N. (1996). Eighteen-month-old children learn words in non-ostensive contexts. Journal of Child Language, 23, 157-176. DOI: 10.1017/ S0305000900010138

Vaish, A., Demir, Ö.E., \& Baldwin, D. (2011). Thirteen- and 18-month-old infants recognize when they need referential information. Social Development, 20, 431-449. DOI: 10.1111/j.1467-9507.2010.00601.x

Vincent-Smith, L., \& Bricker, D. B. W. (1974). Acquisition of receptive vocabulary in the toddlerage child. Child Development, 45, 189-193. DOI: 10.2307/1127767

Wilkinson, K. M., Dube, W. V., \& Mcilvane, W. J. (1998). Fast mapping and exclusion (emergent matching) in developmental language, behavior analysis, and animal cognition research. The Psychological Record 48, 407-422. 
Wittgenstein, L. 1953 Philosophical Investigations, Oxford: Blackwell.

Woodward, A. L., \& Markman, E. M. (1998). Early word learning. In W. Damon, D. Kuhn \& R. Siegler (Eds.) Handbook of Child Psychology, Volume 2, Cognition, Perception and Language (pp. 371-420). New York, NY: John Wiley and Sons.

Wu, Y.C., \& Coulson, S. (2007). How iconic gestures enhance communication: An ERP study. Brain and Language, 101, 234-245. DOI: 10.1016/j.bandl.2006.12.003

Yasuda, T., \& Kobayashi, H. (2010). The role of adults' eye gaze direction in children's learning part names. Handbook on the 12th Annual International Conference of the Japanese Society for Language Sciences (pp. 53-36). 